\title{
OTRA PERSPECTIVA URBANA PARA LA HISTORIA LITERARIA DEL PERÚ: LA 'TAPADA' COMO SÍMBOLO DE LA LIMA COLONIAL
}

\author{
EVA $M^{a}$ VALERO JUAN \\ Universidad de Alicante \\ Eva.Valero@ua.es
}

\section{RESUMEN}

Durante los siglos de la Colonia, la imagen de la mujer limeña, en su atuendo de «tapada», tuvo una importancia cardinal, tanto por su construcción literaria como icono de la ciudad virreinal, como por su utilización para identificar y cohesionar en el siglo XIX y primeras décadas del XX un discurso identitario que fluctuó del ámbito histórico al literario. El presente artículo analiza, a través de fragmentos literarios e históricos principales, la evolución del discurso que construyó dicha imagen, así como los derroteros de la literatura peruana visibles a través del mismo. A ello se une la necesaria reflexión sobre los modos con que la predominante voz masculina ha construido la mencionada historia.

Palabras clave: Lima, tapada, identidad, Flora Tristán, Palma, Mariátegui, Valdelomar.

\section{ABSTRACT}

During the colonial period, the image of the women in Lima, with their covered vestments had great importance, not only as a literary iconic symbol of the city, but also in the use of this image to identify and unify a discourse of identity in the $19^{\text {th }}$ century up to the first decades of the $20^{\text {th }}$ century. This article analyzes the evolution of the discourse which constructed this image and the different paths of Peruvian literature using literaty fragments and historical texts. It is also necessary to reflect on how the predominant male voice has contributed to the contruction of this image.

Keywords: Lima, covered, identity, Flora Tristán, Palma, Mariátegui, Valdelomar.

¡Ob cindad milagrosa

de raro bechizo y de lisura fina, que esconde con rebozo de neblina su gracia recatada y misteriosa, como lueñe Tapada, que deja apenas entrever la rosa y el pálido jazmín de una mejilla, ya la embrujada y dulce maravilla de una sola mirada!
Si una ciudad puede identificarse a través de una imagen cultural que defina su esencia espiritual e histórica, sin duda la figura de la «tapada» es un ejemplo paradigmático para definir la ciudad de Lima durante su historia colonial. Y si esto es así, el motivo de dicha conjunción hay que buscarlo en los textos -literarios e históricos- que construyeron a través de los siglos esa alianza indisoluble. José Gálvez
Eva $M^{a}$ Valero Juan

Doctora en Filología Hispánica por la Universidad de Alicante y Profesora Titular de Literatura Hispanoamericana en la misma. Es autora de Lima en la tradición literaria del Perú. De la leyenda urbana a la disolución del mito (Lleida, Universitat de Lleida, 2003), La ciudad en la obra de Julio Ramón Ribeyro (Alicante, Universidad de Alicante, 2003), Rafael Altamira y la «reconquista espiritual» de América (Cuadernos de América sin nombre, $\left.\mathrm{n}^{\circ} 8,2003\right)$, Tras las huellas del Quijote en la América virreinal. Estudio y edición de textos (Roma, Bulzoni, 2010), así como de numerosos artículos publicados en revistas nacionales e internacionales especializadas en literatura española e hispanoamericana. Es editora de las antologías El Quijote en Perú y El Quijote en México en el Centro Virtual del Instituto Cervantes, y de La casa de cartón de Martín Adán (Huerga y Fierro, 2006).

\footnotetext{
Otra perspectiva urbana para la historia literaria del Perú: la 'tapada' como símbolo de la Lima colonial EVA $M^{a}$ VALERO JUAN
} 


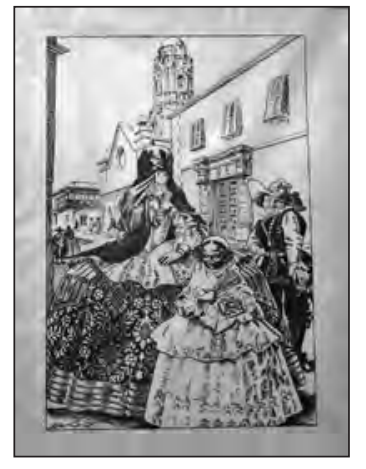

Retrato en la Casa Museo Ricardo Palma (Lima, Miraflores).

1

También Aurelio Miró Quesada, en Lima, tierra y mar, reparó en la elegancia de los prominentes balcones artísticamente labrados $y$ en el ornato exterior de una ciudad americana de abolengo moruno: "Al lado de los balcones fueron multiplicándose, como otra de las características arquitectónicas de Lima, los vivaces azulejos. Los conventos primero, los templos luego y las casas después, se fueron engalanando con esos barros vidriados de colores, en que se unía la gracia de la ciudad con el refulgente sol de Andalucía y el abolengo artístico de las tierras morunas» (1958, pp. 42-43).

2

Raúl Porras Barrenechea nos facilita los datos que muestran la fervorosa religiosidad de la Lima colonial: «El censo del marqués de Montesclaros arrojará sobre un total de 26.441 habitantes, un 10 por 100 de clérigos, canónigos, frailes y monjas. Juan María Gutiérrez podrá decir de Lima que era 'un inmenso monasterio de ambos sexos'». (1994, p. 95).

3

"Para hallar, sin embargo, un discípulo notorio de esta vena es menester traspasar un siglo. [...] Terralla y Landa oyó seguramente las sátiras de Caviedes. No estaban impresas pero corrían por las calles. El mundo descrito por ambos es el mismo» (García Calderón, 1914, p. 35).

\footnotetext{
Otra perspectiva urbana para la historia literaria del Perú: la 'tapada' como símbolo de la Lima colonial

EVA M ${ }^{a}$ VALERO JUAN
}

peruana -la Ciudad de los Reyes que inicialmente fuera aldea de caña y barro-, adquirió paulatinamente su particular fisonomía urbana. $Y$ en el mismo devenir de la transformación de aquella aldea en capital virreinal, la ciudad recién fundada a orillas del Pacífico comenzó a construir su leyenda a través de fragmentos literarios, en Crónicas de Indias o en incipientes versos, en los que se trataba de crear una imagen que imprimiera a la ciudad una dimensión espiritual. En este proceso, la mujer limeña tuvo una importancia cardinal, tanto por su coincidencia con las esencias de la ciudad, como por su utilización para identificar y cohesionar un discurso identitario que fluctuaba del ámbito histórico al literario. A la evolución de ese discurso dedico estas páginas, en las que habrá que reflexionar, finalmente, sobre los modos con que fue construido por la predominante voz masculina. Como veremos, dicho discurso opacó o desintegró otras voces que no convergían con la hegemónica -masculina-, con la construcción de una leyenda urbana en la que el papel otorgado a la mujer no escapaba al estereotipo femenino que a continuación trataré de explicar.

Lima tras el manto encubridor: Alonso Carrió de la Vandera, Ventura García Calderón, Raúl Porras Barrenechea y Luis Alberto Sánchez

Para empezar, hay que recordar que desde fines del siglo de la conquista, el espíritu criollo impuso su anhelo fastuoso a la primitiva sencillez de la aldea fundada por los primeros pobladores, anunciando así el nacimiento de la ciudad barroca: el plano cuadriculado de las calles se vio compensado con el ornamento exterior de casas y palacios, sin olvidar esos campanarios y cúpulas que, como recuerda Raúl Porras Barrenechea, conferían a la ciudad desde la distancia «esa gracia musulmana que ha de sorprender a los viajeros» ${ }^{1}(1994$, p. 95$)$. En esta ciudad de boato, la limeña adquirió un protagonismo indiscutible desde los orígenes, que comenzó a aparecer en los textos derrochando gracia y belleza tras el insinuante y a la vez recatado ropaje de la saya y el manto; una imagen que se construía al mismo tiempo que la capital virreinal continuaba creciendo a lo largo de aquellos primeros siglos de vida en arcos y bóvedas de iglesias, marcando los caminos de avance y crecimiento urbano, y que, por otra parte, le imprimían un aspecto monacal ${ }^{2}$. Algunos historiadores del siglo $\mathrm{XX}$ plantearon el contraste de esta imagen con el sensualismo de la que fue considerada ciudad-mujer por excelencia; por ejemplo, el mismo Porras Barrenechea, al hacer una equiparación implícita entre la figura de la «tapada» y la instantánea de una ciudad que, tras la austeridad de sus muros, escondía la fiesta de sus patios:

...ese ideal de recato y clausura se contagia y se extiende, porque la casa familiar es ascética, reprimida por fuera y alegre y expansiva por dentro, porque la arquitectura adopta esa misma actitud de atisbo y de recato en las celosías moriscas de los balcones, porque las mujeres se tapan el rostro para salir a la calle, y, por último, porque la ciudad misma, ungida de místico recogimiento aprendido en el lírico regazo de las letanías, decide convertirse toda ella, en un inmenso huerto cerrado -hortus clausum- y encerrarse dentro de unas murallas simbólicas que nada defienden, porque los limeños confían, más que en ellas, en la ayuda de Dios. (1965, pp. 381-382)

Esta imagen urbana de huerto cerrado -que venía a coincidir en su esencia con la figura de esa mujer tapada que, lejos del recato de su indumentaria, escondía picardía, coquetería y sensualidad- alcanzó el siglo XVIII, cuando, en palabras del mismo historiador, el aspecto de Lima

sigue siendo austero y sombrío como el de un claustro. Los viejos solares, de portalones solemnes, los zaguanes oscuros y las altas cercas de los monasterios, prestan sombra y silencio a las calles. [...] Pero tras la apariencia grave, el alma de la ciudad se sonreía, como el rostro de la tapada bajo el manto encubridor. [...] Tras de los muros de los conventos surgía la alegre fiesta de los jardines y de los azulejos, y en los claustros propicios el libertinaje triunfaba ya sobre la oración. (1994, p. 97)

En este mismo siglo, un andaluz llegó a Lima, concretamente en 1787. Se trata de Esteban de Terralla y Landa, poeta que escribió versos mordaces y satíricos, que le valieron su consideración como discípulo o continuador de la tradición inaugurada por el conocido como «el Quevedo peruano», Juan del Valle y Caviedes ${ }^{3}$. Nos interesa sobre todo aquí su panfleto Lima por dentro y fuera, uno de los testimonios literarios de aquellos primeros siglos en los que Lima penetra en los espacios de la escritura. La obra es un gran cuadro cos- 
tumbrista salpicado de localismos peruanos, donde caben todos los tipos sociales de la Lima colonial y, entre ellos, la limeña ocupa un lugar de especial relevancia e interés. Terralla, cáustico y socarrón, denuncia en el extenso poema el materialismo imperante en las relaciones humanas y satiriza la frivolidad de las mujeres, descargando todo su sarcasmo en una diatriba contra la ciudad de los virreyes, sus grandezas y miserias.

La sal criolla que caracterizará más tarde a los costumbristas peruanos decimonónicos ya comenzó a derrocharse en cada una de las descripciones de Terralla, pero también en las de otro conocidísimo autor dieciochesco, Alonso Carrió de la Vandera (Concolorcorvo), en su Lazarillo de ciegos caminantes. En las obras de ambos autores la limeña ocupa un lugar preferente, reflejo y prueba del especial protagonismo de la mujer en la Lima del momento. De hecho, tanto Concolorcorvo como Terralla y Landa construyeron las primeras manifestaciones literarias en las que la limeña se sitúa en el centro de la escena. Concolorcorvo describe su vestimenta, la saya que ceñía las caderas y el manto que dejaba un solo ojo al descubierto:

...las limeñas ocultan este esplendor con un velo nada transparente en tiempo de calores, y en el de fríos se tapan hasta la cintura con doble embozo, que en realidad es muy extravagante. Toda su bizarría la fundan en los vaxos, desde la liga hasta la planta del pie. (1980, p. 414)

Sobre esta misma imagen merece recordarse también la descripción que ofrecería dos siglos después Luis Alberto Sánchez de la original vestimenta de las «tapadas» en la obra que dedicó al principal icono limeño del siglo XVIII, La Perricholi, figura a la que más adelante me referiré:

La vida limeña continuaba su crescendo de inquietudes y provocaciones. [...] Las tapadas circulaban luciendo ese invento del Demonio llamado saya, la cual falda, de tan ceñida, modelaba hasta la transparencia las formas de las mujeres, de nalga a tobillo como un guante. Cubierto el rostro, menos un ojo, con la manta finísima, las muy ladinas compensaban a maravilla la poca exposición de sus rostros con la mucha de sus talles y aledaños. (1971, p. 106)

También Porras Barrenechea señaló esta importancia de la limeña en el Siglo de las
Luces, como imagen dominante que resume la esencia misma de la Lima dieciochesca, convirtiéndose de este modo en símbolo principal de la ciudad en este momento:

La hegemonía no la ejercen los emperifollados doctores

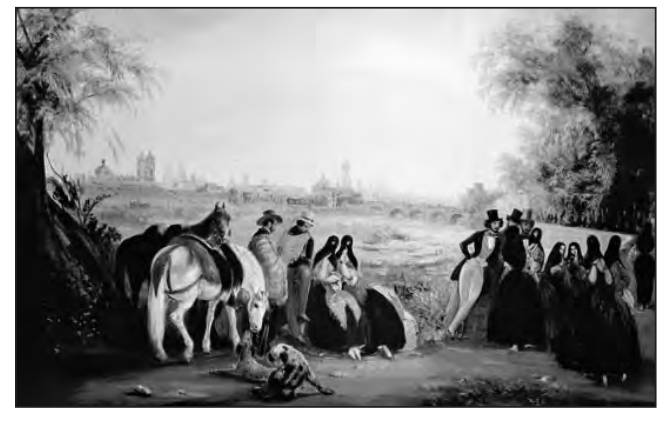
ni los monstruos de erudición que entonces albergaba la Universidad, sino que la atención, el orgullo y el mimo de la ciudad estuvieron concentrados alrededor del más grácil de los personajes: la limeña. Ella resume lo más típico del setecientos limeño, en el alma, en las costumbres y hasta en el traje. Nadie como ella encarna el ingenio, la agilidad incesante, la malicia y la agudeza de la inteligencia criolla. [...] Coqueta, supersticiosa, derrochadora, amante del lujo, del perfume y de las flores, ella domina en el hogar, atrae en los portales y en los estrados de los salones, edifica por su piedad en la iglesia, y en los conflictos del amor, de la honra y de la política es el más cuerdo consejero, cuando no el actor más decidido, que obliga a algún desleal a cumplir su palabra o pone en jaque al mismo Virrey del Perú. (1994, p. 98)

Esta última alusión hace referencia al personaje mítico de la historia limeña dieciochesca: Micaela Villegas, apodada «la Perricholi», que se transformó en paradigma de la descripción realizada por Porras Barrenechea ${ }^{4}$. Esta comedianta, amante del famoso virrey catalán Manuel Amat y Junyent, fue con el tiempo una de las figuras principales de la leyenda de la ciudad, pasando a engrosar no sólo las páginas de la literatura limeña posterior, sino también las de la literatura y la ópera francesas. De hecho, la fascinación de este personaje encandiló a escritores como Prosper Mérimée, quien en 1829 relató algunas de sus aventuras en Le Carrosse du Saint-Sacrement (obra que inspiró una ópera de 1948 a Henry Busser y en 1953 el film de Jean Renoir Le Carrosse d'or), y a compositores como Jacques Offenbach, que dedicó a este personaje legendario la opereta titulada, precisamente, La Périchole, de 1868. Como observa Mario Castro Arenas, la Lima del siglo XVIII, afrancesada, sensual y licenciosa, tuvo como protagonista de excepción el espectáculo escénico, y Micaela Villegas, en el candelero de este escenario, «es la espuma de un proceso social que tipifica o, si se quiere, pervierte, a las
4

Sobre el protagonismo de las mujeres en la Lima del siglo XVIII, véase Aurelio Miró Quesada, "La 'Perricholi' y las limeñas», en Lima, Ciudad de los Reyes, pp. 68-72.

\footnotetext{
Otra perspectiva urbana para la historia literaria del Perú: la 'tapada' como símbolo a 'tapada' como símbolo
de la Lima colonial EVA M ${ }^{a}$ VALERO JUAN
} 


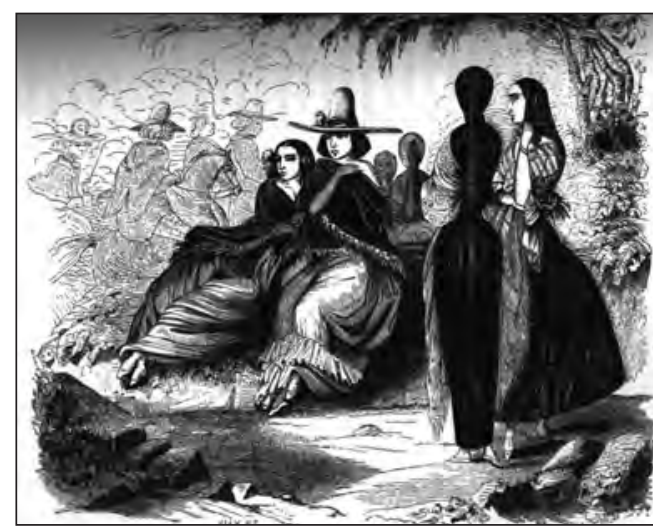

Max Radiguet. mujeres criollas y mestizas de las clases populares. La influencia francesa ha refinado la cualidad carismática de la malicia y coquetería de la mujer limeña» (1965, p. 27).

En cuanto a la literatura de tema limeño que dedicó sus páginas a esta protagonista de la Lima del Virrey Amat, hay que recordar en primer lugar a Ricardo Palma, que le escribió la tradición titulada «Genialidades de la 'Perricholi'» (1894, pp. 299-307). Construida en las páginas del tradicionista como emblema de la Lima del setecientos, resulta de especial interés recordar el apunte de otro escritor principal de comienos del siglo XX, Ventura García Calderón, que escribió una novela en francés titulada La Périchole (1959). Pero la referencia que quiero destacar se encuentra en otra de sus obras, Vale un Perú (1939), donde apuntó que la Perricholi resumía la esencia frívola, pícara y poderosa de las tapadas para convertirse no sólo en icono principal de la Lima dieciochesca, sino en símbolo de la peruanidad integral:

Toda la fama ambulante de las tapadas, durante un siglo de boato y galantería, iba a polarizarse en torno de una mujer venida de provincia. La más famosa limeña, la más típica es una serrana -y debemos bendecir estos aciertos de la casualidad. [...] Sin mucha sutileza podemos ver en ella una armoniosa y viable sintesis de Perú cuando reúne la energía de nuestras altiplanicies a esa sonrisa frívola de Lima, peligrosa porque no toma nada en serio. (1939, p. 121) (La cursiva es mía)

Otro libro emblemático sobre la vida de la actriz es el ya citado de Luis Alberto Sánchez titulado La Perricholi, donde el crítico e historiador nos ofrece, junto a la biografía de la que él llamó «la Cenicienta limeña» (1971, p. 116), el cuadro suntuoso de esta Lima afrancesada, el empaque y el lujo de sus mujeres:

Ellas, españolas o mestizas, usaban riquísimas telas y abundantes encajes: cuajaban sus dedos de sortijas; hacían tintinear las pesadas pulseras a cada movimiento de sus brazos; deslumbraban con el brillo de sus diademas y collares de perlas, brillantes y piedras preciosas [...]
En 1745, Lima lucía cierto empaque de ciudad grande. La vía pública, poblada de cafés y con notoria vida galante, había roto el dique conventual del siglo anterior. Se hablaba de los tiempos idos con cierto desdén y arrogancia. (p. 16)

En definitiva, la limeña imprime el sello característico a la Lima del XVIII -y entre ellas, «la Villegas irremediablemente constituía algo característico de Lima y de una época» (Sánchez, 1971, p. 148)-. Así se refleja en la literatura del siglo ilustrado, pues cuando la urbe emerge en los textos del período, la mujer amanece con una omnipresencia insólita, como figura inseparable de la fisonomía de la ciudad, no sólo de su ambiente sino, lo que resulta no menos interesante, de su misma arquitectura, tal y como vio Porras Barrenechea:

La picardía del embozo, las jugarretas que con él realizaban las limeñas, daban a las calles el aspecto de un baile de máscaras. Y fue tal ese amable absolutismo, durante el siglo XVIII, que la villa misma pareció construida por el capricho tiránico de la mujer y bajo el dictado de su implacable coquetería.

Hay una íntima correspondencia entre el ambiente de la ciudad, entre la arquitectura misma de ésta y el alma de la limeña. La severidad y aridez de afuera contrastaban con la alegría y desenvoltura de adentro. Muros severos y portalones oscuros resguardaban la andaluza fiesta de los jardines, como la picaresca sonrisa de la limeña se escondía bajo el manto encubridor. (1994, pp. 98-99)

Esta Lima, en cierta medida secreta y misteriosa, se construyó por tanto no sólo en textos del siglo XVIII sino en obras de recuperación de la memoria histórica que se desarrollarían con la necesidad de definición de una identidad para la nación independiente, fundamentalmente hacia finales del siglo XIX, tras la Guerra del Pacífico (1879); tendencia que persistiría en dicho empeño a lo largo del siglo XX en obras citadas como las de Ventura García Calderón, Raúl Porras Barrenechea o Luis Alberto Sánchez.

El último florecer de las 'tapadas': Max Radiguet, Flora Tristán, Ricardo Palma y Luis Alayza y Paz Soldán

Llegamos por este camino hasta el siglo XIX para descubrir en la imagen de la ciudad la prueba más contundente de la pervivencia 
del antiguo estatus colonial en la nueva república independiente, es decir, para adivinar en dicha imagen los problemas de una independencia insuficiente y epidérmica. Efectivamente, cuando el fervor revolucionario se disipó tras la guerra emancipadora, Lima recobró la antigua idiosincrasia de la apacible Ciudad de los Reyes y, con ella, sus costumbres coloniales. Así, el viajero francés Max Radiguet -escritor y dibujante- se sorprendería por esa permanencia de hábitos arcaicos, que dejó impresos en su obra Souveniers de l'Amerique Espagnole, publicada en 1856. En sus descripciones y en sus dibujos de nuevo las protagonistas siguen siendo las limeñas, que mantenían su imagen de «tapadas», con la pervivencia de la saya y el manto, del mismo modo que las formas arquitectónicas continuaban fieles a la tradición colonial y, sobre todo, de la misma forma en que los privilegios de clase se mantenían inalterables: «Nada parecía advertirnos -observa Radiguet-, en medio de esta población retozona y radiosa, que nos hallábamos en el corazón de una ciudad atormentada y empobrecida por treinta años de luchas anárquicas» (1965, p. 288)5. Y cuando se centra en las tapadas señala la exclusividad de la saya y el manto:

Después del chocolate espumante y de las dos tostadas, desayuno frugal de los países españoles, mi jornada se abría y comenzaba cada mañana con un paseo en la Plaza Mayor. El movimiento diario se coloreaba de infinitos matices. Gracias a las tapadas se volvía a encontrar ahí, a pleno sol, el atractivo picante y el encanto misterioso de un salón de baile de máscaras. No nos cansábamos de admirar esos trajes raros, en medio de los cuales el vestido europeo, hay que confesarlo, hacía una muy triste figura. Ese vestido en el Perú no es sino el índice de una condición elevada, y el limeño se siente feliz cuando puede dejar el poncho para seguir las modas francesas. Las mujeres se resisten felizmente a esa influencia extranjera y se las ve ostentar con una encantadora coquetería, en medio de todos esos peruanos vestidos a la europea, las irresistibles seducciones del traje nacional. (Radiguet, 1971)

También la mítica Flora Tristán, cuando llegó desde París a Lima en 1833, se admiró del atuendo de las limeñas. Y a pesar de haber sufrido los ataques del arraigado conservadurismo de la sociedad peruana (que la rechazaba por sus ideas progresistas hasta el punto de condenar a la quema en la plaza pública de Arequipa su obra principal) hubiera querido

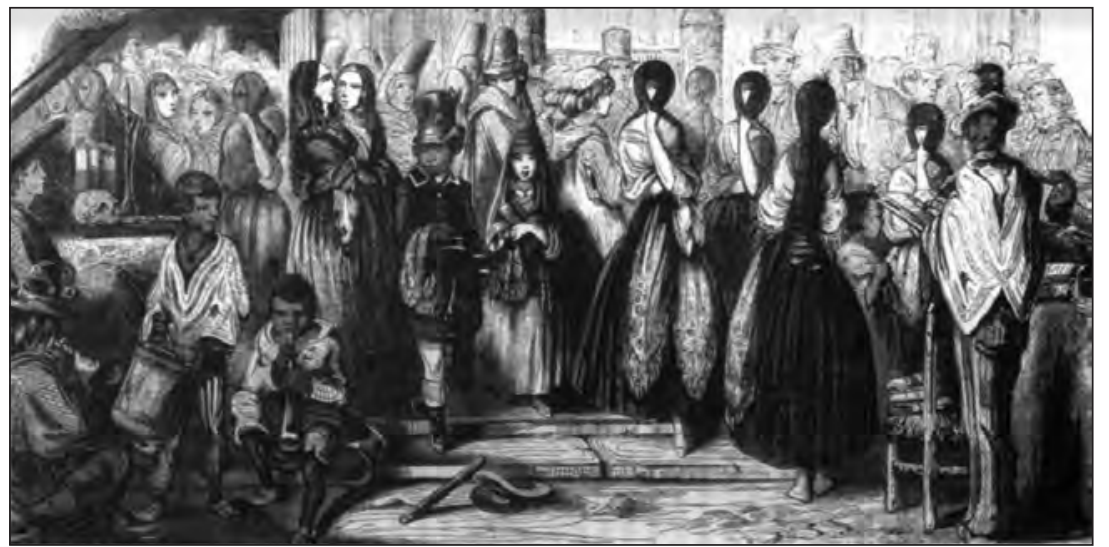

Salida de misa. Por Max Radiguet.

conservar esa indumentaria que pronto desaparecería. Gracias a ella, y en concreto a sus Peregrinaciones de una paria (1837), Europa pudo conocer la gracia y el misterio de las «tapadas», descritos en el capítulo "Lima y sus costumbres», del que podemos recordar las siguientes líneas:

No hay lugar sobre la tierra en donde las mujeres sean más libres y ejerzan mayor imperio que en Lima. Reinan allí exclusivamente. Es de ellas de quien procede cualquier impulso. [...] Su vestido es único. Lima es la única ciudad del mundo en donde ha aparecido. (2000, pp. 420-421)

Como vemos, el tono de Flora Tristán incide, en su línea feminista, en el carácter dominante de las mujeres en la dimensión global de la sociedad limeña, así como en la exclusividad que su vestido consigue imprimir a la ciudad. Sin embargo, tras una prolija descripción de la saya y el manto en la que vuelven a reiterarse los atributos de seducción y malicia de esta vestimenta, añade finalmente que a pesar de que en Lima «la mujer tiene sobre el hombre una superioridad incontestable», es apremiante la necesidad de la educación; idea que en su desarrollo hace surgir una visión de superficialidad de la limeña que viene a coincidir con las manifestaciones masculinas citadas en estas páginas, pero con una derivación crítica que marca una clara diferencia:

...cuando esas limeñas encantadoras que no han puesto ningún ideal elevado en las actitudes de su vida, después de haber electrizado las imaginación de los jóvenes extranjeros, llegan a mostrarse tales como son, con el corazón hastiado, el espíritu sin cultura, el alma sin nobleza y gustando solo del dinero... des-
5

Entre los viajeros que visitan Lima en esta época hay que destacar también a otro francés, el cónsul A. de Botmiliau, quien retrata en sus escritos la decadencia de la ciudad tras la Independencia: «Restos de damasco rojo, último testimonio de la prosperidad perdida, y algunas pinturas al fresco, reemplazan, sobre las paredes agrietadas por los temblores, las ricas tapicerías... Nada más modesto que esas mansiones, últimos santuarios de la sociedad limeña anterior a la Independencia. Y sin embargo, el orgullo de los antiguos conquistadores aparece todavía en la fría dignidad con que sus moradores soportan la miseria». Cit. en Ugarte Elespuru (1967, p. 23). 


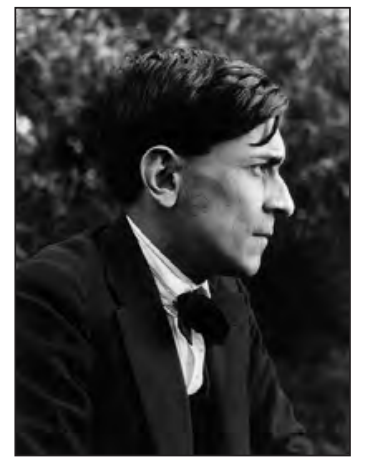

José Carlos Mariátegui. truyen al instante el brillante prestigio de fascinación que sus encantos produjeron. (p. 424)

Ahora bien, esta crítica referida fundamentalmente al destierro de la mujer de los ámbitos educativos, fue minimizada por autores posteriores para hacer prevalecer la visión encandilada de Flora Tristán ante la imagen de las «tapadas»; por ejemplo cuando Ventura García Calderón escribe lo siguiente:

Al regresar prepara el libro en que Europa va a conocer, pintadas por una mano magistral, la gracia y donosura de las limeñas. Quizá nadie ha hablado en francés con más pertinencia y gentil entusiasmo de sus paisanas de la saya y el manto. Si las encuentra menos letradas de lo que había presumido, en cambio su natural despejo, así como la libertad que han recobrado en la vida de relación, la seduce por entero. Precisamente Flora se ha acercado a ellas en el minuto mismo en que van a despojarse de su crisálida fastuosa. Por una casualidad feliz ella es testigo fraternal de una Lima en vías de transformarse y desde el tinglado de París le cuenta al mundo, antes de su eclipse, aquel resplandor de la gracia. Los que leyeron el libro de París se entusiasmaron y, si hemos de creer lo que dice el Sr. Pompery en un artículo de l'Artiste publicado en 1838, algunas parisienses empezaron a llevar la saya y el manto. (1914, pp. 156-157)

Unas décadas más tarde, tras la Guerra del Pacífico en 1879, la ciudad se convirtió en el escenario de la derrota, y los primeros avances urbanísticos impulsados desde mediados de siglo, durante los gobiernos de Castilla y Balta, quedaron truncados ante esta dura debacle. Así, la protohistoria de la modernidad en Lima quedaría sepultada por la guerra. Aurelio Miró Quesada nos presenta aquella Lima enlutada, cuya desgracia la despojó de sus galas coloniales, entre las más preciadas, la de las «tapadas», que emergen en los textos convertidas definitivamente en icono de la Lima colonial:

La guerra del Pacífico, cargada para el Perú a un mismo tiempo de infortunio y de gloria, vino no sólo a golpear duramente los ánimos, sino -en un campo más modesto- a detener los avances de Lima. Hubo pobreza, desasosiego íntimo, dolor callado; y en lo que se refiere a los aspectos urbanos, desdén por lo ornamental y lo superfluo y gusto severo por lo práctico. Lima perdió u olvidó sus viejas galas; y como antes se había encubierto con el manto sutil de las «tapadas», ahora mostró solemnemente sus vestiduras austeras de duelo. (1946, p. 87)
Esta derrota generó una literatura pasatista en la que una generación de escritores lloraron en sus páginas la pérdida del pasado de la Lima colonial. Algunos críticos sitúan el origen de esta tendencia en las Tradiciones Peruanas de Ricardo Palma -a pesar de que sus cultores reemplazaron las irónicas sonrisas del tradicionista por el tono quejumbroso y pesimista-, entre las que encontramos, para el caso que nos ocupa, la titulada «La tradición de la saya y el manto», narración más cercana en este caso al costumbrismo que al relato. Palma pretendió en sus páginas hacer memoria de esta moda femenina remontándose al año 1560 hasta llegar al siglo XIX, para darnos el testimonio directo de su desaparición. Pero lo que más nos interesa es la manera en que el tradicionista describe dicha moda como una de las características principales y exclusivas que identifican, diferencian y confieren personalidad propia a la Lima de la Colonia:

Tratándose de la saya y el manto, no figuró jamás en la indumentaria de provincia alguna de España ni en ninguno de los reinos europeos. Brotó en Lima tan espontáneamente como los hongos en un jardín.

[...] Nadie disputa a Lima la primacía, o mejor dicho la exclusiva, en moda que no cundió en el resto de América...

En el Perú mismo, la saya y el manto fue tan exclusiva de Lima, que nunca salió del radio de la ciudad. $\mathrm{Ni}$ siquiera se la antojó ir de paseo al Callao, puerto que dista dos leguas castellanas de la capital. (1994, pp. 625-626)

En este ejemplo comprobamos el afán de Palma por la captación de lo autóctono limeño, así como la cerrazón de una Lima exclusiva cuya costumbre en la vestimenta femenina «nunca salió del radio de la ciudad»; exclusividad que hemos visto destacada también por Radiguet y por Flora Tristán. El anhelo de distinción es equiparable a la esencia de la «tradición», que se instauró como género propio y, por primera vez en la historia de la literatura del Perú, como una literatura diferente; al igual que la saya y el manto, la «tradición» «nunca figuró en provincia alguna de España ni en ninguno de los reinos europeos», y fue fundamental para el nacimiento de una literatura nacional. De este modo, la imagen de la «tapada» es utilizada como un recurso identitario esencial para el proyecto americanista de Palma. 
Un penúltimo ejemplo, que sí debe encuadrarse dentro de la literatura pasatista que penetró hasta bien entrado el siglo $\mathrm{XX}$, lo encontramos en las crónicas de Luis Alayza y Paz Soldán, recogidas bajo el título Mi país ( $4^{a}$ serie: ciudades, valles y playas de la costa del Perú) (1945), donde este escritor dedicó un apartado a «Lima: Evocaciones de la urbe y sus alrededores». Aquí, Alayza rememora historias y costumbres de la antigua «urbe religiosa y galante» $(1945$, p. 8$)$ y, asimismo, registra la evolución de «una Lima que se va» (título de la obra de José Gálvez que inauguró este tópico de la literatura peruana en el año 1921). En sus páginas palpita «el corazón insepulto de la Lima colonial», «el fantasma de la Colonia» (p. 23), cuando reescribe el tópico de la Lima que desaparece y se transforma, una imagen urbana que nuevamente es femenina, como la tapada que protagonizó su historia dieciochesca:

Las ciudades tienen sexo. [...] nadie confundirá la marcial arrogancia de Buenos Aires [...] con la devoción y donaire de Lima, que en las mañanas reza y comulga, y en las noches, disfrazada bajo la saya y el manto, escapa por la puerta secreta, para urdir intrigas de política y travesuras amorosas. (p. 36)

Lima y la tapada vuelven a aparecer en esta imagen en la que la fusión entre ambas -a través de sus tenaces vasos comunicantes-adquiere una especial relevancia, pues la ciudad, por fin, se ha personificado en la figura de la limeña. Cubierta con tan misterioso ropaje, Lima -intrigante y caprichosa- adquiere definitivamente las mismas cualidades que la tapa$\mathrm{da}$, protagonista indiscutible de su escenario callejero durante los tiempos del virreinato.

La serenata ante los balcones del virreinato: José Carlos Mariátegui y Abraham Valdelomar

La última referencia a las tapadas que he seleccionado para este recorrido, se encuentra en una curiosa obra teatral que fue escrita por dos jovencísimas promesas de la literatura y la cultura del Perú, Abraham Valdelomar y José Carlos Mariátegui. Bajo los pseudónimos de Julio de la Paz y Juan Croniqueur, respectivamente, la obra, titulada precisamente Las tapadas, fue publicada en 1915 y se presenta, sin duda irónicamente -tanto por el subtítulo como por el argu- mento y la forma en que está escrita-, como «Poema colonial en un acto y cuatro cuadros, en prosa y verso original», y más adelante como «ensayo» o "poema sentimental o galante» evocador de una «época caballeresca». La dedicatoria a Ricardo Palma -a quien Mariátegui trataría de desvincular de la tradición hispanista-pasatista que intentó anexarse su figura a través principalmente de la reivindicación de José de la Riva-Agüero- resulta también curiosa por la imitación que en ella se encuentra de la retórica de la denominada literatura pasatista contra la que ambos intelectuales se posicionaron, con especial beligerancia en el caso de Mariátegui: «A través de vuestras historias -escriben dirigiéndose a Palma- [...] llegó hasta nuestras almas, sensibles a la intensa sugestión del pasado, la visión de una poética edad lejana, no por romancesca menos real» (Mariátegui, 1994, p. 2233 $)^{6}$; un sentimiento de deuda con el gran tradicionista sobre el que abundan a continuación con el reconocimiento a una literatura -las Tradiciones peruanas- de la que se enorgullecen.

«Romanticismo y trovadorismo mal trasegados»-utilizando las palabras del propio Mariátegui, más de una década después, en su «Proceso de la literatura» (Mariátegui, 1996, p. 215)-, que serían el principal caballo de batalla del «Amauta», son curiosamente en Las tapadas la tonalidad principal. Desde mi punto de vista, ello evidencia la más que probable perspectiva irónica de esta obra, no sólo por ser una recreación de la literatura pasatista que Mariátegui criticó con dureza, sino también por el especial humorismo que, por otra parte, definió la literatura de Valdelomar; humorismo que el propio Mariátegui señaló y analizó en el capítulo de los Siete ensayos de interpretación de la realidad peruana que dedicó a su compañero? .

Resumiendo el argumento, la obra relata con mucho sarcasmo la lucha de dos caballeros por el amor de una dama, uno de ellos peruano y el otro, ya en la decrepitud de su vida, español. No por casualidad el vencedor será el joven caballero peruano, que primero es derrotado por la fuerza (al recibir una herida de la espada toledana de don Fernando en el primer duelo) y que sin embargo después consigue vencer al español, y quedarse con el amor de doña Isabel, en una partida de ajedrez, es decir, a través de la inteligencia. Un argumento como este bien puede leerse

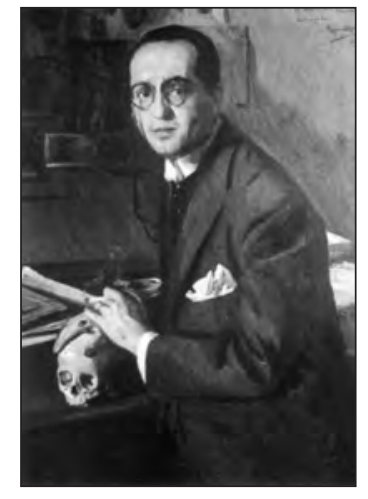

Abraham Valdelomar.

6

Cito siempre Las tapadas a partir de su edición en Mariátegui total (1994).

7

"Uno de los elementos esenciales del arte de Valdelomar es su humorismo. La egolatría de Valdelomar era en gran parte humorística. Valdelomar decía en broma casi todas las cosas que el público tomaba en serio». (Mariátegui, 1996, p. 257).

\footnotetext{
Otra perspectiva urbana para la historia literaria del Perú: la 'tapada' como símbolo 'tapada' como símbol
de la Lima colonial EVA Ma VALERO JUAN
} 
como sátira sobre la historia de la conquista de América, vencida por las armas, pero vencedora finalmente con su Independencia.

En cuanto a la imagen de «la tapada» en la obra, desde la misma dedicatoria aparece ya una primera definición en la que se añade un matiz que hasta el momento no había tenido: «hetaira criolla, apasionada y voluptuosa». Además, la definición como hetaira no es ocasional, pues se ratifica después en la caracterización de los siguientes versos del prólogo:

Criollas recatadas bajo de saya y manto, barraganas de un fraile austero e inquisidor, en cuyos ojos negros se leía el quebranto de fogosas pasiones y vigilias de amor. (p. 2234)

Como hetaira, o barragana, aparecerá después un personaje de la obra, doña Mercedes, con el atuendo de tapada, que no lucirá sin embargo la protagonista, doña Isabel, caracterizada, según el estereotipo tradicional de la amada, por la pureza, el recato y la honra.

Por otro lado, la imagen de la tapada se utiliza además, nuevamente, como símbolo de la Lima del coloniaje (con «perspectiva de ciudad española: campanarios, minaretes, miradores, etc.») (p. 2234) que permite a los autores recrear poéticamente lo que Mariátegui denominaría en sus Siete ensayos, la «serenata ante los balcones del virreinato", en referencia a la mediocre poesía colonial de sello español. La recreación es clara desde el comienzo del Cuadro Primero, cuando el Coro da inicio a la función:

Bajo del balcón florido
aguarda tu caballero
viene a ofrecerte tendido
su corazón de trovero» (p. 2234)

Esta escena se repite a lo largo de la obra en diversas serenatas bajo el balcón de la señora, Isabel. Pero como ya he adelantado, no es ésta la representante de la tapada, sino doña Mercedes, que aparece vestida de saya y manto y ante cuya imagen don Fernando exclama:

Mercedes, vuestro manto no sabe disfrazaros a mis ojos. Adivino tras él, el vuestro encanto que enciende tan fanáticos antojos. (p. 2238)
Y más adelante:

La que luce mejor la saya y manto porque aumenta con ellos el encanto divino y misterioso de sus ojos. (p. 2241)

Esta figura de la tapada, en otros momentos ligada a la hermosura, el capricho y la sensualidad, se construye efectivamente en conjunción con la ciudad levítica, que ejerce una irresistible atracción con su «quietud sonora». Pero lo interesante es que esta conjunción se realiza en el contexto de una obra que, en su línea argumental, estaba prefigurando el ideario posterior de Mariátegui en su «Proceso de la literatura» (el séptimo de sus Siete ensayos), cuando plantea el mencionado motivo de «la serenata ante los balcones del virreinato» como metáfora de la poesía colonial (que desde su punto de vista es española) y cuya supervivencia cultural -la del colonialismo, vinculado al españolismo, al aristocratismo y al espíritu reaccionario- trató de prolongarse con la tendencia al pasatismo sustentada por José de la Riva-Agüero (Vid. Rovira, 1995, p. 112). El motivo se encuentra en el capítulo de su «Proceso de la Literatura» titulado «El colonialismo supérstite»:

En un país dominado por los descendientes de los «encomenderos» y los oidores del virreinato, nada era más natural, por consiguiente, que la serenata bajo sus balcones. [...] Los mediocres literatos de una república que se sentía heredera de la Conquista no podían hacer otra cosa que trabajar por el lustre y brillo de los blasones coloniales». (Mariátegui, 1996, pp. 214-215)

Y en esta obra los jóvenes Mariátegui y Valdelomar encontraron un ángulo humorístico para ridiculizar ese colonialismo tan de moda en las primeras décadas del siglo XX que ellos, finalmente, consiguieron relegar, tanto a través del movimiento «Colónida» encabezado por Valdelomar en torno a la revista de título homónimo iniciada en 1916, como desde el vanguardismo indigenista abanderado por Mariátegui en la revista Amanta a partir de 1926; movimientos desde los que, como es bien sabido, se dio entrada a un período de modernización inaplazable en la literatura del Perú.

En todo caso, al realizar la humorada de Las tapadas en 1915, cuando aquella revolución literaria estaba a punto de eclosionar, ambos dieron nueva vida a aquellas legenda- 
rias tapadas a las que, sin embargo, decidieron desligar de la aureola mítica que tal literatura pasatista les había conferido. Por lo que esta primeriza obra teatral de Valdelomar y Mariátegui resulta ser un punto de llegada idóneo en estas páginas para visualizar la evolución literaria de la tapada limeña, desde su conversión en icono de la capital virreinal, hasta su desmitificación a comienzos de un siglo XX en el que ese colonialismo del que la saya y el manto fueron insignia principal ya no debía tener cabida en el proyecto nacional de futuro.

Por todo ello, como hemos podido comprobar en las obras recorridas -todas ellas pertenecientes a voces masculinas a excepción de la de Flora Tristán-, nos encontramos ante fragmentos literarios o de reconstrucción histórica que permiten adivinar los trayectos de la historia literaria del Perú; y que por otro lado ofrecen un claro perfil de la posición de la mujer en la Lima colonial, ceñida en principio a un papel meramente decorativo, aunque influyendo en ocasiones en la vida pública, pero siempre desde la retaguardia social. En dichos fragmentos se constata un protagonismo de las mujeres que las convierte en símbolo principal de la Lima colonial, pero los atributos con los que se las define constantemente -coquetería, malicia, capricho, tiranía, picardía-, hacen que ese protagonismo contenga una evidente, aunque solapada, carga peyorativa. Así definida, la mujer viene a metaforizar la idea de una ciudad que se caracteriza en su historia por dichos atributos: elitista, frívola y encerrada por las legendarias murallas que, en la historia de Lima durante los siglos del coloniaje, la mantuvieron como reducto urbano que vivió de espaldas y a expensas del Perú real. Ahora bien, más allá de esta cuestión, marcada evidentemente por la tradicional visión hegemónica masculina, resulta de especial interés constatar cómo se construye en los textos la identificación entre Lima y las «tapadas», convirtiendo a la capital peruana en esa ciudad-mujer cuyos muros y mantos encubrieron, en la mayor parte de los textos, la vida real de la historia limeña virreinal y republicana.

\section{Bibliografía}

Alayza y Paz Soldán (1945), Luis, Mi país (4 ${ }^{a}$ serie: ciudades, valles y playas de la costa del Perú), Lima, Talleres Gráficos Publicidad-Americana.
Carrió de la Vandera, Alonso «Concolorcorvo» (1980), El Lazarillo de ciegos caminantes (1773), ed. de A. Lorente Medina, Madrid, Editora Nacional.

Castro Arenas, Mario (1965), La novela peruana y la evolución social, Lima, Cultura y Libertad.

García Calderón, Ventura (1914), La literatura peruana (1535-1914), en la Revue Hispanique, tomo XXXI, New York, París.

- (1939), Vale un Perú, París, Desclée.

Mariátgegui, José Carlos y Abraham Valdelomar (Julio de la Paz y Juan Croniqueur) (1994), Las tapadas (1915), en José Carlos Mariátegui, Mariátegui total, Tomo II, Lima, Empresa Editora Amauta, pp. 22332250.

Mariátegui, José Carlos (1996), Siete ensayos de interpretación de la realidad peruana, México, Era.

Miró Quesada, Aurelio (1946), «La 'Perricholi’ y las limeñas», en Lima, Ciudad de los Reyes, Buenos Aires, Emecé.

- (1958), Lima, tierra y mar, Lima, Juan Mejía Baca.

- (1946), Lima, Cindad de los Reyes, Buenos Aires, Emecé.

Palma, Ricardo (1894), Tradiciones peruanas, tomo II, Barcelona, Montaner y Simón.

- (1994), Tradiciones permanas (selección), Madrid, Cátedra.

Porras Barrenechea, Raúl (1965), Pequeña antología de Lima. El río, el puente y la alameda, Lima, Instituto Raúl Porras Barrenechea.

- (1994), «Perspectiva y panorama de Lima», en La marca del escritor, México, Fondo de Cultura Económica.

Radiguet, Max (1965), «Lima en 1844», en Raúl Porras Barrenechea, Pequeña antología de Lima, Lima, Instituto Raúl Porras Barrenechea.

- (1971), Lima y la sociedad peruana, Alicante, Biblioteca Virtual Miguel de Cervantes, 2001. Edición basada en la de Lima, Biblioteca Nacional del Perú. URL: http://www.cervantesvirtual.com/servlet/ SirveObras/90253950982392717243457/ p0000001.htm\#4. Consulta realizada el 24 de julio de 2010.

Rovira, José Carlos (1995), Entre dos culturas. Voces de identidad hispanoamericana, Alicante, Universidad de Alicante, Servicio de Publicaciones.

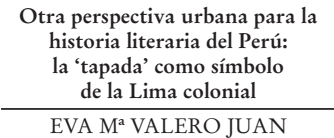

Otra perspectiva urbana para la la 'tapada' como símbolo EVA Ma VALERO JUAN 
Sánchez, Luis Alberto (1971), La perricholi, Buenos Aires-Santiago de Chile, Editorial Francisco de Aguirre.

Tristán, Flora (2000), Peregrinaciones de una paria, Lima, Biblioteca Nacional del Perú.
Ugarte Elespuru, Juan Manuel (1967), Lima y lo limeño, Lima, Editorial Universitaria. Valero Juan, Eva $\mathrm{M}^{\mathrm{a}}$, Lima en la tradición literaria del Perú. Entre la leyenda urbana y la disolución del mito, Lleida, Universitat de Lleida, 2003.

Otra perspectiva urbana para historia literaria del Perú la 'tapada' como símbolo de la Lima colonial

EVA Ma VALERO JUAN 